\section{Editor-in-Chief \\ Barbara McLain - (retired Prof.) \\ University of Hawaii, USA}

The Israeli Journal of Aquaculture (IJA) is an interdisciplinary journal that is dedicated to sharing new research and tested applications of aquaculture

The IJA is devoted to scholarly articles for improved aquaculture practices and related industries

The IJA is a peer-reviewed, open-access, electronic journal

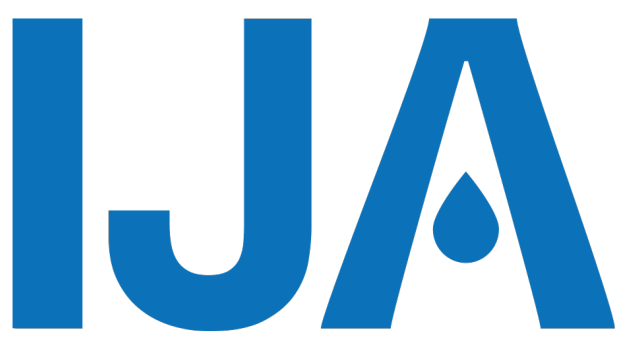

\section{The () Israeli Journal of Aquaculture}

An interdisciplinary online Open Access scientific journal

Published by the

\section{AquacultureHub}

A non-profit organization 501c3

http://www.aquaculturehub.org

in partnership with the

\section{University of Hawaii at Manoa} Library

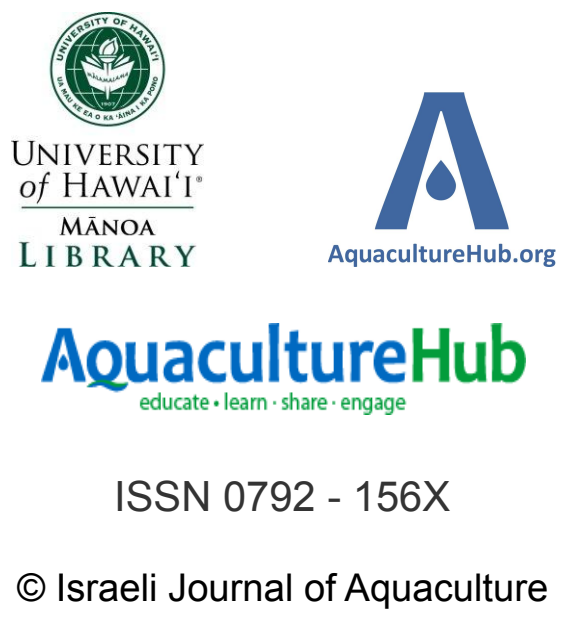


The Israeli Journal of Aquaculture - Bamidgeh, IJA_71.2019.1632, 8 pages

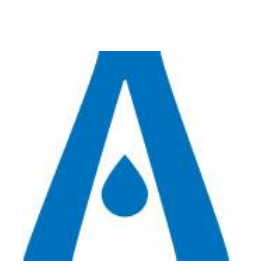

Produced by the AquacultureHub non-profit Foundation the IJA is an open-access, scientific journal, published on http://www.aquaculturehub.org/group/israelijournalofag uaculturebamidgehija

To read papers free of charge, please register online at the above website.

Sale of IJA papers is strictly forbidden.

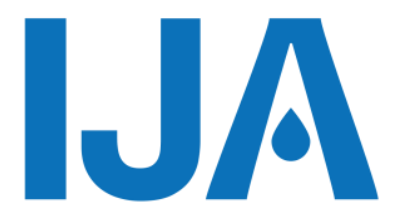

\title{
Effect of Ammonia Exposure on the Non-Specific Immunity of Fresh Water Pearl Mussel Hyriopsis cumingii
}

\author{
Xia $H^{1,2,3}$, Yang $\mathrm{P}^{1} *$, Liu $L^{1}$, Luo $\mathrm{Y}^{1,2,3}$, Sun $\mathrm{Y}^{3}$, Wang $\mathrm{W}^{1}$, Yuan $\mathrm{M}^{1}$, \\ Liu W1
}

\author{
${ }^{1}$ Collaborative Innovation Center for Efficient and Health Production of \\ Fisheries in Hunan Province, Hunan University of Arts and Science, Hunan \\ Changde 415000. \\ ${ }^{2}$ State Key Laboratory of Developmental Biology of Freshwater Fish, \\ Hunan Normal University, Hunan Changsha 410081. \\ ${ }^{3}$ Hunan Provincial Key Laboratory for Microbial Molecular Biology, \\ Hunan Normal University, Hunan Changsha 410081.
}

Keywords: Hyriopsis cumingii; pearl mussel; ammonia-N; immune function; lysozyme activity

\begin{abstract}
Ammonia- $\mathrm{N}$, the principal end-product of protein catabolism, is an important environmental toxic factor in ponds. Elevated environmental ammonia- $\mathrm{N}$ is very toxic to aquatic animals and has a deleterious effect on their immune system. However, its effect on their immune system remains unclear. In this study, the effects of ammonia- $\mathrm{N}(0,5,10$ and $30 \mathrm{mg} / \mathrm{L})$ on immune responses of Fresh Water Pearl Mussel Hyriopsis cumingii were determined. When exposed to $5 \mathrm{mg} / \mathrm{L}$ ammonia-N lysozyme activity increased significantly. Superoxide dismutase activity was highest in the $5 \mathrm{mg} / \mathrm{L}$ group followed by the $10 \mathrm{mg} / \mathrm{L}$ group. The marked decrease of Lysozyme activity of Fresh Water Pearl Mussel Hyriopsis cumingii in $10 \mathrm{mg} / \mathrm{L}$ and $30 \mathrm{mg} / \mathrm{L}$ ammonia- $\mathrm{N}$ groups suggests that the higher concentrations of ammonia- $N$ reduces or inhibits their non-specific immunity. Compared to the control group, superoxide dismutase activity in $30 \mathrm{mg} / \mathrm{L}$ ammonia also decreased significantly. When exposed to $5 \mathrm{mg} / \mathrm{L}$ ammonia- $\mathrm{N}$, catalase, acid phosphatase and alkaline phosphatase activity enhanced. In the $10 \mathrm{mg} / \mathrm{L}$ and $30 \mathrm{mg} / \mathrm{L}$ group, ammonia- $\mathrm{N}$ decreased significantly The lysozyme, catalase, acid phosphatase and alkaline phosphatase activity showed a similar tendency. This suggests that in $H$. cumingii immunostimulatory response is enhanced at low ammonia$\mathrm{N}$ concentrations. The results of this study provide a theoretical basis for disease prevention in the freshwater pearl mussel.
\end{abstract}

* Corresponding authors. email address: xiahu@webmail.hzau.edu.cn; yph588@163.com 


\section{Introduction}

The bivalve mollusk Hyriopsis cumingii is the main freshwater pearl mussel species in China (Huang et al., 2016). Pearls produced by H. cumingii are smooth, bright in color, round in shape, and have high economic value (Wang et al., 2019). China is the largest producer of pearls in the world and more than $80 \%$ of these are obtained from $\mathrm{H}$. cumingii (Bai et al., 2014). Like most invertebrates, H. cumingii lack a typical adaptive immune system and their ability to fend off pathogens relies mainly on humoral immune factors in the hemolymph, including a variety of enzymes, antibacterial peptides, opsonins, lectins, and complement components (Iwanaga and Lee, 2005).

The level of waterborne ammonia in natural waters and in culture systems has harmful effects on aquatic animals (Lemarie et al., 2004). Ammonia is produced as a metabolic waste product of protein catabolism and/or generated from the decomposition of organic material, industrial emission or produced by micro-organisms (Diricx et al., 2013). High environmental ammonia (HEA) not only hinders ammonia excretion in fish but also causes an uptake of ammonia from the environment (Diricx et al., 2013). Hence, during HEA, fish are confronted simultaneously with accumulation of endogenous ammonia and uptake of exogenous ammonia, causing adverse effects on their performance and welfare (Eddy, 2005; Randall and Tsui, 2002). Waterborne ammonia exists in two forms, as unionized ammonia $\left(\mathrm{NH}_{3}\right)$ and as an ionized form $\left(\mathrm{NH}_{4}{ }^{+}\right.$) (Randall and Tsui, 2002). The sum of $\mathrm{NH}_{3}$ and $\mathrm{NH}_{4}{ }^{+}$comprises the total ammonia concentration. Throughout this paper, the term "ammonia- $\mathrm{N}$ " is used to refer to total $\mathrm{NH}_{3}+\mathrm{NH}_{4}{ }^{+}$, whereas these chemical symbols refer to the individual components of ammonia gas $\left(\mathrm{NH}_{3}\right)$ and ammonium ion $\left(\mathrm{NH}_{4}^{+}\right)$.

The health of aquatic animals is dependent on the complex interactions between the environment, pathogens, and the host (Dang et al., 2012). Ammonia is one of the major environmental pollutants in fish culture especially in recirculation systems (Cheng et al., 2015). It has been reported that the concentration of ammonia increases directly with culture period and might reach levels as high as $46 \mathrm{mg} / \mathrm{L}$ in intensive aquaculture systems (Chen et al., 1988). Elevated ammonia in aquaculture systems can be taken up through the gills by diffusion and cause very high concentrations in the body fluids (Eddy, 2005). Additionally, elevated concentration of ammonia in pond water can cause fish growth reduction, tissue erosion and degeneration, immune suppression, and high mortality (Benli et al., 2008; Lia et al., 2014). Many previous studies have demonstrated that suboptimal environmental conditions, such as elevated environment ammonia- $\mathrm{N}$, decreases the immunity of some crabs and fish (Yue et al., 2010, Xia et al., 2018). However, the effect of ammonia-N on the immune system of bivalve mollusks remains unclear. This study aimed at determining the effect of ammonia exposure on the immune parameters of Hyriopsis cumingii.

Experimental layout

\section{Materials and Methods}

$H$. cumingii mussels, averaging $50 \pm 2.5 \mathrm{~g}$ in body weight, were collected from Hanshou pearl breeding base. Before the beginning of the experiments, the mussels were acclimatized and quarantined in aerated freshwater plastic tanks kept at $26 \pm 2{ }^{\circ} \mathrm{C}$ for two weeks. The experiment was approved by the guidelines of Institutional Animal Care and Use Committees (IACUC) of Hunan University of Arts and Science, Changde, China.

Experimental design

The tested ammonia- $\mathrm{N}$ concentrations were: $0,5,10$, and $30 \mathrm{mg} / \mathrm{L}$. The test solutions were prepared by dissolving ammonium chloride $\left(\mathrm{NH}_{4} \mathrm{Cl}\right)$ in de-chlorinated tap water. Prior to the experiment, a total of 360 mussels were allocated into four groups and randomly stocked in 12 glass tanks $\left(0.95 \times 0.6 \times 0.5 \mathrm{~m}^{3}\right)$. There were 30 individuals in each tank and three repetitions for each group.

During the experiment, ammonia- $\mathrm{N}$ concentration was measured every $12 \mathrm{~h}$ using an ammonia nitrogen detection kit purchased from Nanjing Jian Cheng Bioengineering Institute (China). Approximately one-third of the water was replaced every day and ammonium chloride solution was subsequently added to maintain a relatively constant concentration of ammonia-N. $\mathrm{pH}$, water temperature, and dissolved oxygen were 
controlled at levels of $7.5 \pm 0.2,26 \pm 2{ }^{\circ} \mathrm{C}$ and $6.0 \pm 0.2 \mathrm{mg} / \mathrm{L}$, respectively. The mussels were kept under a constant photoperiod ( $12 \mathrm{~h}$ light: $12 \mathrm{~h}$ darkness).

The experiment was conducted for $30 \mathrm{~d}$. Sampling for various immunological parameters was carried out on the 30th day. 9 individuals were selected randomly from each group, three from each replicate. The livers of the mussels were collected and weighed, and $2 \mathrm{ml}$ of normal saline was added. The homogenated tissues were then centrifuged 10 minutes at $4000 \mathrm{r} / \mathrm{min}$. The supernatant was stored at $-20^{\circ} \mathrm{C}$ for catalase (CAT), alkaline phosphatase (AKP), acid phosphatase (ACP), superoxide dismutase (SOD), and lysozyme activity tests.

Lysozyme activity

Lysozyme activity was measured using the turbidity assay. Lysozyme standard product powder $(80,000 \mathrm{U} / \mathrm{mg})$ was used as a standard, and $1 \mathrm{mg}$ lyophilized micrococcus lysodeikticus with sodium phosphate buffer $(\mathrm{pH} 5.75)$ was used as substrate. $20 \mu \mathrm{L}$ plasma sample was added to $2 \mathrm{~mL}$ of the substrate, and the reduction in the transmittance at $530 \mathrm{~nm}$ was determined after $20 \mathrm{~s}$ and $8 \mathrm{~min}$ incubation. One unit of lysozyme activity was defined as an increase in transmittance of 0.001 per min.

Superoxide dismutase (SOD) activity

Superoxide dismutase (SOD) activity was measured by its ability to inhibit superoxide radical-dependent reactions using the Ransod Kit (Randox, Crumlin, UK). A reference standard SOD was supplied with the Ransod Kit. One unit of SOD was defined as the amount required to inhibit the rate of xanthine reduction by $50 \%$. Specific activity was expressed as SOD units $\mathrm{m} / \mathrm{L}$.

Catalase, Alkaline phosphatase, and Acid phosphatase activity

In the experiments, we measured catalase (CAT), alkaline phosphatase (AKP), and acid phosphatase activity (ACP) of the liver. These were determined using the Diagnostic Reagent Kits purchased from Nanjing Jian Cheng Bioengineering Institute (China).

Statistical analysis

Data are presented as mean value \pm standard error (SE); mean values of treatments were compared using the one-way analysis of variance by Duncan's test of STATISTICA software package (Version 6.0, Statsoft, Inc.). Differences between the control and the treatment groups were considered statistically significant at $P<0.05$.

\section{Lysozyme activity}

\section{Results}

After the ammonia challenge, the lysozyme activity of tested mussels is shown in Fig. 1. Lysozyme activity of $H$. cumingii in the control group was $3.28 \mathrm{U} / \mathrm{ml}, 4.13 \mathrm{U} / \mathrm{ml}$ in $5 \mathrm{mg} / \mathrm{L}$ ammonia-N group, $2.40 \mathrm{U} / \mathrm{ml}$ in $10 \mathrm{mg} / \mathrm{L}$ ammonia- $\mathrm{N}$ group and $2.25 \mathrm{U} / \mathrm{ml}$ in $30 \mathrm{mg} / \mathrm{L}$ ammonia-N group. $H$. cumingii when exposed to $5 \mathrm{mg} / \mathrm{L}$ ammonia- $\mathrm{N}$ had increased significantly the lysozyme activity but decreased significantly in $10 \mathrm{mg} / \mathrm{L}$ and $30 \mathrm{mg} / \mathrm{L}$ (Fig. 1).

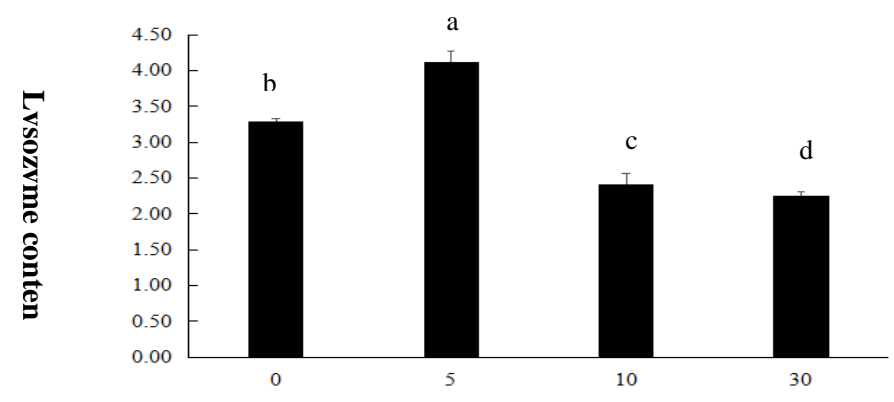

Ammonia-N (mg/L)

Fig. 1. Lysozyme activity of $H$. cumingii when exposed to ammonia- $\mathrm{N}(0,5,10$ and $30 \mathrm{mg} / \mathrm{L})$. Data are presented as mean \pm SE $(n=9)$. Differences were determined by one-way analysis of variance (ANOVA). Different letters above bars represented significant difference at the levels of $p<0.05$, and same letters above bars indicated no significant difference. 
Superoxide dismutase (SOD) activity

The superoxide dismutase (SOD) activity of $H$. cumingii, when exposed to ammonia is shown in Fig. 2. Superoxide dismutase activity was $0.78 \mathrm{U} / \mathrm{ml}$ in the $0 \mathrm{mg} / \mathrm{L}$ group, $3.00 \mathrm{U} / \mathrm{ml}$ in the $5 \mathrm{mg} / \mathrm{L}$ group, $1.05 \mathrm{U} / \mathrm{ml}$ in the $10 \mathrm{mg} / \mathrm{L}$ group and $0.64 \mathrm{U} / \mathrm{ml}$ in the 30 $\mathrm{mg} / \mathrm{L}$ group. Compared with control group, this activity in the $30 \mathrm{mg} / \mathrm{L}$ group decreased significantly (Fig. 2).

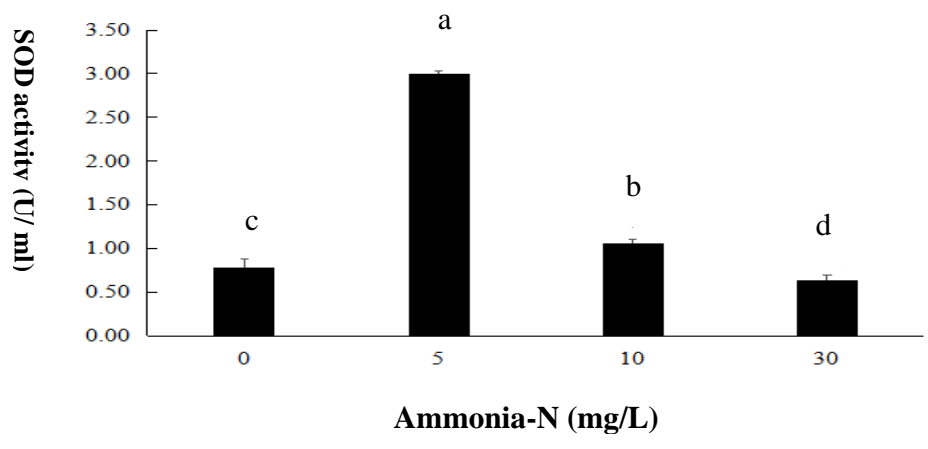

Fig. 2. Superoxide dismutase (SOD) activity of $H$. cumingii when exposed to ammonia-N $(0,5,10$ and $30 \mathrm{mg} / \mathrm{L})$. Data are presented as mean \pm SE $(n=9)$. Differences were determined by one-way analysis of variance (ANOVA). Different letters above bars represented significant difference at the levels of $p<0.05$, and same letters above bars indicated no significant difference.

\section{Catalase (CAT) activity}

The catalase (CAT) activity of $H$. cumingii when exposed to ammonia- $\mathrm{N}$ is shown in Fig. 3.In the control group it was $31.96 \mathrm{U} / \mathrm{ml}$, in the $5 \mathrm{mg} / \mathrm{L}$ group it was $37.70 \mathrm{U} / \mathrm{ml}$ followed by $20.42 \mathrm{U} / \mathrm{ml}$ in the $10 \mathrm{mg} / \mathrm{L}$ group and $4.74 \mathrm{U} / \mathrm{ml}$ in the $30 \mathrm{mg} / \mathrm{L}$ group. When exposed to $5 \mathrm{mg} / \mathrm{L}$ (Fig. 3). Catalase activity in the $10 \mathrm{mg} / \mathrm{L}$ and $30 \mathrm{mg} / \mathrm{L}$ groups decreased significantly (Fig. 3).

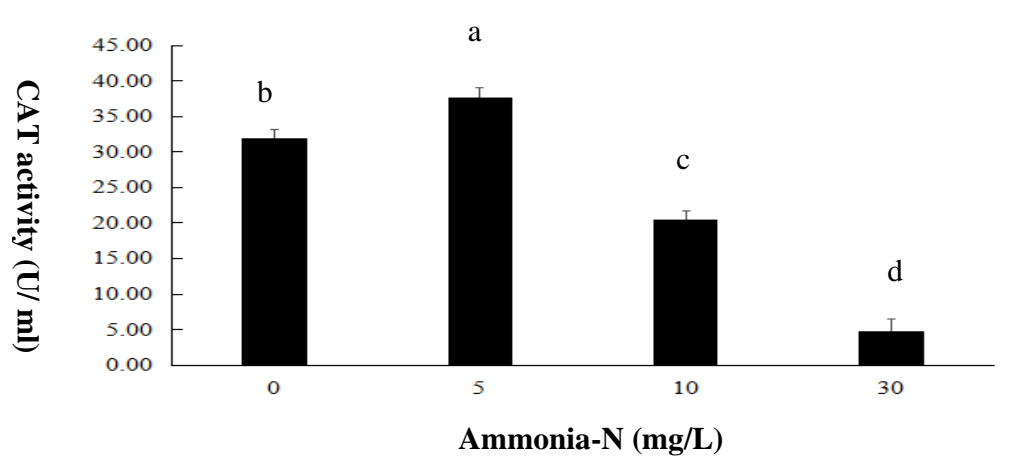

Fig. 3. Catalase activity (CAT) of $H$. cumingii when exposed to ammonia- $\mathrm{N}(0,5,10$ and $30 \mathrm{mg} / \mathrm{L})$. Data are presented as mean \pm SE $(n=9)$. Differences were determined by one-way analysis of variance (ANOVA). Different letters above bars represented significant difference at the levels of $\mathrm{p}<0.05$, and same letters above bars indicated no significant difference.

Acid phosphatase (ACP) activity

The acid phosphatase (ACP) activity after ammonia- $\mathrm{N}$ exposure is shown in Fig. 4. In the control group it was $0.07 \mathrm{U} / \mathrm{ml}, 0.04 \mathrm{U} / \mathrm{ml}$ in the $0.10 \mathrm{U} / \mathrm{ml}$ group, and $0.03 \mathrm{U} / \mathrm{ml}$ in the $30 \mathrm{mg} / \mathrm{L}$. When exposed to $5 \mathrm{mg} / \mathrm{L}$ ammonia-Nthe acid phosphatase activity enhanced significantly (Fig. 4) but decreased significantly in the $10 \mathrm{mg} / \mathrm{L}$ and $30 \mathrm{mg} / \mathrm{L}$ groups (Fig. 4). 


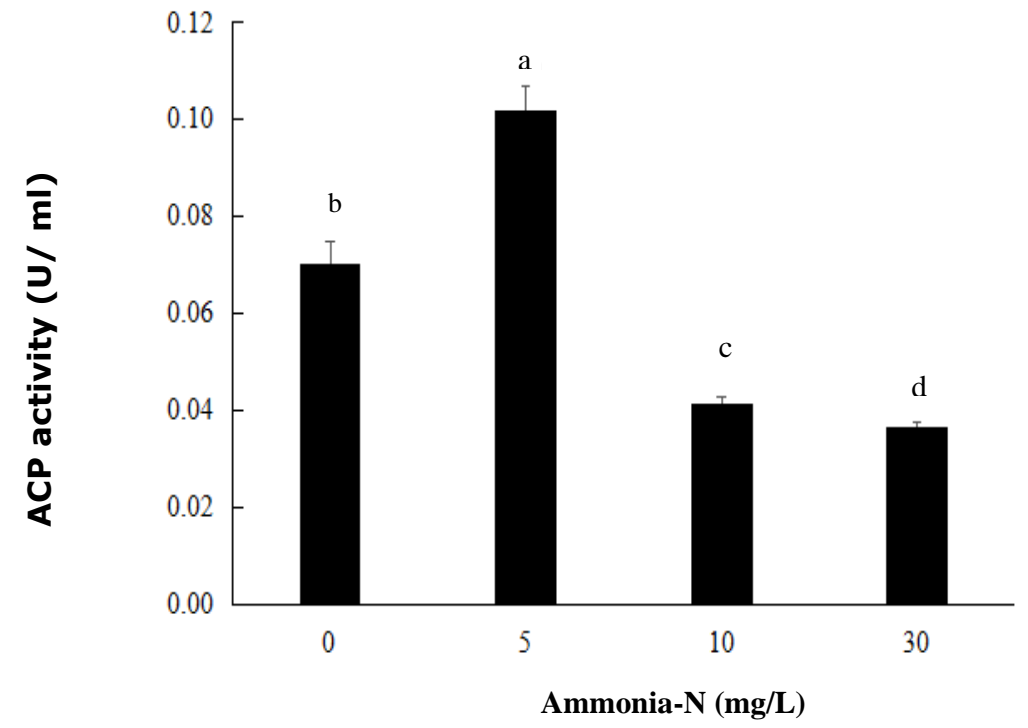

Fig. 4. Acid phosphatase activity (ACP) of $H$. cumingii when exposed to ammonia- $N(0,5,10$ and $30 \mathrm{mg} / \mathrm{L})$. Data are presented as mean \pm SE $(n=9)$. Differences were determined by one-way analysis of variance (ANOVA). Different letters above bars represented significant difference at the levels of $p<0.05$, and same letters above bars indicated no significant difference.

Alkaline phosphatase (AKP) activity

The alkaline phosphatase (AKP) activity after ammonia- $\mathrm{N}$ exposure is shown in Fig. 5. In the control group it was $0.14 \mathrm{U} / \mathrm{ml}, 0.19 \mathrm{U} / \mathrm{ml}$ in the $5 \mathrm{mg} / \mathrm{L}$ group, $0.03 \mathrm{U} / \mathrm{ml}$ in the $10 \mathrm{mg} / \mathrm{L}$ group and $0.03 \mathrm{U} / \mathrm{ml}$ in $30 \mathrm{mg} / \mathrm{L}$ ammonia- $\mathrm{N}$ group. $H$. cumingii when exposed to $5 \mathrm{mg} / \mathrm{L}$ ammonia- $\mathrm{N}$ increased significantly alkaline phosphatase activity (Fig. 5). Alkaline phosphatase activity of $H$. cumingii in $10 \mathrm{mg} / \mathrm{L}$ and $30 \mathrm{mg} / \mathrm{L}$ ammonia- $\mathrm{N}$ had decreased significantly (Fig. 5).

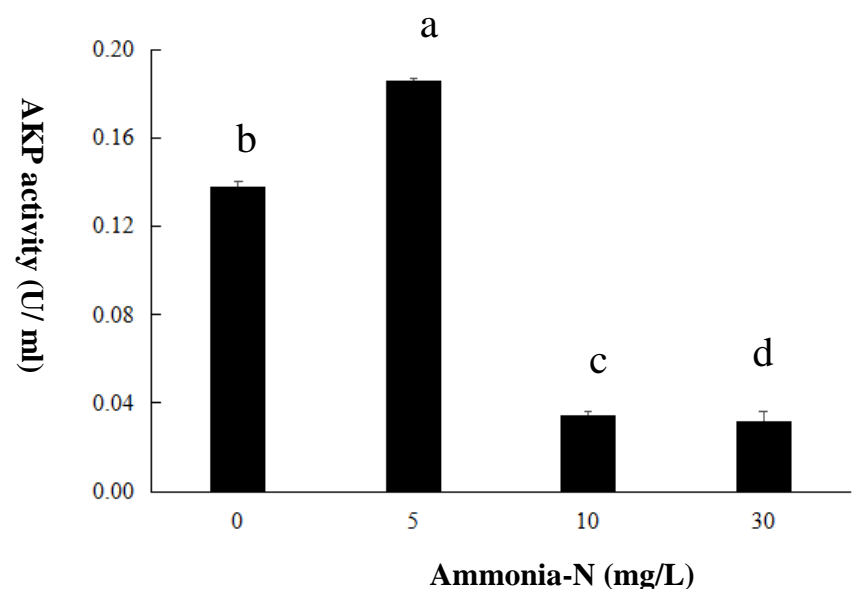

Fig. 5. Alkaline phosphatase activity $(A K P)$ of $H$. cumingii when exposed to ammonia- $N(0,5,10$ and $30 \mathrm{mg} / \mathrm{L})$. Data are presented as mean $\pm \mathrm{SE}(\mathrm{n}=9)$. Differences were determined by one-way analysis of variance (ANOVA). Different letters above bars represented significant difference at the levels of $p<0.05$, and same letters above bars indicated no significant difference.

\section{Discussion}

The present study determined, for the first time, the effect of ammonia exposure on the non-specific immunity of $H$. cumingii. The activities of lysozyme, superoxide dismutase, catalase, acid phosphatase, and alkaline phosphatase were assessed after exposure of $H$. cumingii to various ammonia-N concentrations in water after 30 days. The 
activities of these five enzymes increased at the lowest ammonia- $\mathrm{N}$ concentration tested $(5 \mathrm{mg} / \mathrm{ml})$ and decreased at higher ammonia- $\mathrm{N}$ concentrations $(10 \mathrm{mg} / \mathrm{ml}$ and $30 \mathrm{mg} / \mathrm{ml})$. These results suggest that high ammonia levels could influence the expression or activity of key enzymes associated with non-specific immunity functions in $\mathrm{H}$. cumingii.

Lysozyme is an antimicrobial enzyme and an important humoral factor that enhances non-specific immunity in animals. Lysozyme activity can be enhanced at relatively low concentrations of pollutants (Low and Sin, 1996). The lysozyme serum activity significantly increased in the low dosage in the MC groups. In the present study when exposed to $5 \mathrm{mg} / \mathrm{L}$ ammonia- $\mathrm{N}$ it increased significantly due to the enhanced release of lysozyme from the phagocytes that were activated in damaged immune organs (Qiao et al., 2013). However, in the high dose exposure group, the effect of immunotoxicity exceeded the regulation response of the fish, thus weakening their ability to synthesize lysozyme (Kong et al., 2011). The marked decrease of the Lysozyme activity in the 10 $\mathrm{mg} / \mathrm{L}$ and $30 \mathrm{mg} / \mathrm{L}$ ammonia- $\mathrm{N}$ the high dosage groups reduced or inhibited its nonspecific immunity function.

Superoxide dismutase (SOD) is an enzyme that catalyzes the conversion of the superoxide $\left(\mathrm{O}_{2}^{-}\right)$radical into oxygen and hydrogen peroxide. Superoxide and hydrogen peroxide play important microbicidal roles in non-specific disease resistance (Song and Hsieh, 1994; Downs et al., 2001). As such, SOD is an important antioxidant defense. Several other studies have observed ammonia exert an influence on superoxide anion production or SOD activity in aquatic animals. The production of superoxide anion in the freshwater prawn (Macrobrachium rosenbergii) and whiteleg shrimp (Litopenaeus vannamei) was stimulated following exposure of the animals to ammonia-N (Cheng and Chen, 2002; Liu and Chen, 2004). In studies that examined bighead carp (Hypophthalmichthys nobilis) larvae, Chinese mitten crab (Eriocheir sinensis), and submerged Vallisneria natans, low $\mathrm{NH}_{3}-\mathrm{N}$ concentrations were shown to elevate $\mathrm{SOD}$ activity, whereas high $\mathrm{NH}_{3}-\mathrm{N}$ levels caused reduced SOD activity (Sun et al., 2012; Hong et al., 2007; Wang et al., 2008). SOD activity in the liver and white muscle of Nile tilapia (Oreochromis niloticus) exposed to ammonia-N was significantly increased, which was proposed to manage the elevated formation of reactive oxygen species (ROS) (Hegazi et al., 2010). In the present study, superoxide dismutase activity of $H$. cumingii in $5 \mathrm{mg} / \mathrm{L}$ and $10 \mathrm{mg} / \mathrm{L}$ ammonia- $\mathrm{N}$ increased significantly while decreased significantly at $30 \mathrm{mg} / \mathrm{L}$ ammonia-N, which is in line with the results found in previous studies (Sun et al., 2012; Hong et al., 2007; Wang et al., 2008). It indicates that a lower dose of ammonia-N could induce organs to produce increased amounts of ROS, and SOD activity was elevated to deal with excessive ROS (Hegazi et al., 2010); however, under higher doses of ammonia$\mathrm{N}$, SOD showed lower activity, possibly due to the inability of SOD to overcome extremely high levels of ROS, and excessive ROS could in turn inactivate SOD activity (Bagnyukova et al., 2006).

Catalase breaks down the harmful by-product hydrogen peroxide into water and oxygen and is a key enzyme that protects cells from oxidative damage by ROS (Pandey et al., 2003). A similar result to the present study was observed in bighead carp, where

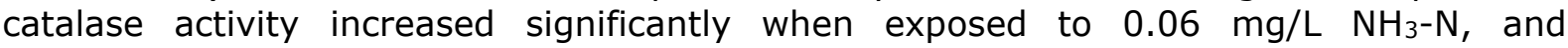
decreased when exposed to $0.264 \mathrm{mg} / \mathrm{L} \mathrm{NH}_{3}-\mathrm{N}$ (Sun et al., 2012).

Increased phosphatase activity indicated a higher breakdown of the energy reserve, which was utilized for fish growth and survival (Sahu et al., 2008). Various effects have been observed to influence phosphatase activities in fish. Increased acid and alkaline phosphatase activities were observed following Aeromonas hydrophilia infection of blunt snout bream (Megalobrama amblycephala) and climbing perch (Anabas testudineus) (Xia et al., 2017, Das et al., 2009). Another study showed that alkaline phosphatase activity was increased in Labeo rohita fish that were fed turmeric (Sahu et al., 2008).

The findings of this study indicated that high ammonia exposure caused significant reductions in the activity or production of enzymes participating in the non-specific immune response of $H$. cumingii. Further research into the mechanisms of these interactions will help provide a better understanding of the effects that ammonia has on the health and disease prevention of $H$. cumingii, and possibility other aquatic animals. 


\section{Acknowledgements}

The present study was supported by Hunan Natural Science Foundation (Grant No. 2018JJ3373), China Postdoctoral Science Foundation(2019M652748), Innovation fund project of Hunan University of Arts and Sciences: harmless breeding technology of freshwater pearls (2017KC002), Hunan University of Arts and Science Scientific Research and Development Fund (407/G01008), State Key Laboratory of Developmental Biology of Freshwater Fish (Grant No.2017KF007) and the National Natural Science Foundation of China (Grant No. 31572619).

The authors declare no conflict of interests.

\section{References}

Bai Z.Y., Wang G.L., Liu X.J., Li J.L., 2014. The status and development trend of freshwater pearl seed industry in China. J Shanghai Ocean Univ, 23: 874-881.

Bagnyukova T.V., Chahrak O.I., Lushchak V.I., 2006. Coordinated response of goldfish antioxidant defenses to environmental stress, Aquat. Toxicol, 78: 325-331.

Benli A.C.K., Köksal G., Özkul A., 2008. Sublethal ammonia exposure of Nile tilapia (Oreochromis niloticus L.): effects on gill liver and kidney histology. Chemosphere, 72: 1355-1358.

Cheng W., Chen J.C., 2002. The virulence of Enterococcus to freshwater prawn Macrobrachium rosenbergii and its immune resistance under ammonia stress. Fish Shellfish Immunol, 12: 97-109.

Cheng C.H., Yang F.F., Ling R.Z., Liao S.A., Miao Y.T., Ye C.X., Wang A.L., 2015. Effects of ammonia exposure on apoptosis, oxidative stress and immune response in puff erfish (Takifugu obscurus). Aquat Toxicol, 164: 61-71.

Chen J.C., Liu P.C., Lin Y.T., 1988. Super intensive culture of red-tailed shrimp Penaeus penicillatus. J World Aquacult Soc, 19: 127-131.

Dang V.T., Speck P., Benkendorff K., 2012. Influence of elevated temperatures on the immune response of abalone, Haliotis rubra. Fish Shellfish Immunol, 32(5):732-40.

Das B.K., Debnath C., Patnaik P., Swain D.K., Kumar K., Misrhra B.K., 2009. Effect of $\beta$-glucan on immunity and survival of early stage of Anabas testudineus (Bloch). Fish Shellfish Immunol, 27(6): 678-683.

Diricx M., Sinha A.K., Liew H.J., Mauro N., Blust R., De Boeck G., 2013. Compensatory responses in common carp (Cyprinus carpio) under ammonia exposure: a dditional effects of feeding and exercise. Aquat Toxicol, 15: 142-143:123-37.

Downs C., Fauth J.E., Woodley C.M., 2001. Assessing the health of grass shrimp (Palaemonetes pugio) exposed to natural and anthropogenic stressors: a molecular biomarker system. Mar Biotechnol, 3: 380-397.

Eddy F.B., 2005. Ammonia in estuaries and effects on fish. J Fish Biol, 67: 1495-1513.

Huang Y., Wang W., Ren Q., 2016. Identification and function of a novel C1q domaincontaining (C1qDC) protein in triangle-shell pearl mussel (Hyriopsis cumingii). Fish Shellfish Immunol, 58: 612-621.

Hong M., Chen L., Sun X., Gu S., Zhang L., Chen Y., 2007. Metabolic and immune responses in Chinese mitten-handed crab (Eriocheir sinensis) juveniles exposed to elevated ambient ammonia. Comp Biochem Physiol C, 145: 363-369.

Hegazi M.M., Attia Z.I., Ashour O.A., 2010. Oxidative stress and antioxidant enzymes in liver and white muscle of Nile tilapia juveniles in chronic ammonia exposure. Aquat. Toxicol, 99: 118-125.

Iwanaga S., Lee B.L., 2005. Recent advances in the innate immunity of invertebrate animals. Mol Biol Evol, 38: 128-150.

Kong X.H., Wang S.P., Jiang H.X., Nie G.X., Li X.J., 2011. Changes of the activities of enzymes related to immunity and the content of malondialdehyde during embryonic development of goldfish Carassius auratus. J Fishery Sci China, 18: 1293-1298 (in Chinese). 
Lemarie G., Dosdat A., Coves D., Dutto G., Gasset E., Ruyet J.P., 2004. Effect of chronic ammonia exposure on growth of European seabass (Dicentrarchus labrax) juveniles. Aquaculture, 229: 471-491.

Lia M., Yu N., Qin J.G., Li E., Du Z.Y., Chen L.Q., 2014. Effects of ammonia stress, dietary linseed oil and Edwardsiella ictaluri challenge on juvenile darkbarbel catfish Pelteobagrus vachelli. Fish Shellfish Immunol, 38: 158-165.

Liu C.H., Chen J.C., 2004. Effect of ammonia on the immune response of white shrimp Litopenaeus vannamei and its susceptibility to Vibrio alginolyticus. Fish Shellfish Immunol, 16(3): 321-34.

Low K.W., Sin Y.M., 1996. In vivo and in vitro effects of mercuric chloride and sodium selenite on some non-specific immune responses of blue gourami, Trichogaster trichopterus (Pallus). Fish Shellfish Immunol, 6: 351-362.

McKenzie D.J., Shingles A., Taylor E.W., 2003. Sub-lethal plasma ammonia accumulation and the exercise performance of salmonids. Comp Biochem Physiol A: Mol Integr Physiol, 135: 515-526.

Pandey S., Parvez S., Sayeed I., Haque R., Bin-Hafeez B., Raisuddin S., 2003. Biomarkers of oxidative stress: a comparative study of river Yamuna fish Wallago attu (Bl.\& Schn.), Sci Total Environ. 309: 105-115.

Qiao Q., Liang H.L., Zhang X.Z., 2013. Effect of cyanobacteria on immune function of crucian carp (Carassius auratus) via chronic exposure in diet. Chemosphere, 90: 11671176

Randall D.J., Tsui T.K., 2002. Ammonia toxicity in fish. Mar Pollut Bull, 45, 17-23.

Wang G., Liu F., Xu Z., Ge J., Li J., 2019. Identification of Hc- $\beta$-catenin in freshwater mussel $H$. cumingii and its involvement in innate immunity and sex determination. Fish Shellfish Immunol, 91:99-107.

Song Y.L., Hsieh Y.T., 1994. Immunostimulation of tiger shrimp Penaeus monodon haemocytes for generation of microbicidal substances: analysis of reactive oxygen species. Dev Comp Immunol, 18: 201-209.

Sun H., Lü K., Minter E.J., Chen Y., Yang Z., Montagnes D.J., 2012. Combined effects of ammonia and microcystin on survival, growth, antioxidant responses, and lipid peroxidation of bighead carp Hypophthalmythys nobilis larvae. J Hazard Mater, 30: 221-222:213-9.

Wang C., Zhang S.H., Wang P.F., Hou J., Li W., Zhang W.J., 2008. Metabolic adaptations to ammonia-induced oxidative stress in leaves of the submerged macrophyte Vallisneria natans (Lour.) Hara. Aquat. Toxicol, 87: 88-98.

Xia H., Song T., Wang L., Jiang L.S., Zhou Q.T., Wang W.M., Liu L.G., Yang P.H., Zhang X.Z., 2018. Effects of dietary toxic cyanobacteria and ammonia exposure on immune function of blunt snout bream (Megalabrama amblycephala). Fish Shellfish Immunol, 78: 383-391

Xia H., Tang Y., Lu F.H., Luo Y.S., Yang P.H., Wang W.B., Jiang J.G., Li N., Han Q., Liu F., Liu L.G., 2017. The effect of Aeromonas hydrophila infection on the non-specific immunity of blunt snout bream (Megalobrama amblycephala). Central European J Immunol, 42(3): 239-243

Yue F., Pan L., Xie P., Zheng D., Li J., 2010. Immune responses and expression of immune-related genes in swimming crab Portunus trituberculatus exposed to elevated ambient ammonia-N stress. Comp Biochem Physiol A Mol Integr Physiol, 157(3): 246-51. 